\title{
Conference/Seminars
}

\section{Issues in Methodology of Islamic Thought}

Safar 9-12, 1410/September 11-14, 1989

During the period from Șafar 9-12, 1410 H. / September 11-14, 1989 A.D., a seminar on the "Issues in Methodology of Islamic Thought" was held at Amir Abd al Qadir University of Islamic Studies (Qusantinah, Algeria). The seminar was organized by the university in conjunction with the International Institute of Islamic Thought (Washington, D.C.). A group of professors and students of both sexes from Amir Abd al Qadir University, as well as from the Central University, participated in the seminar activities. The opening session was attended by representatives from Qusantinah Province, the $\mathrm{Na}$ tional Liberation Front, the Municipal Council, and the Religious Committee. Speeches were delivered by Dr. 'Ammar al Talibi, the University President and Chairman of the seminar; Dr. Gamal El-Din Attia, Academic Advisor of the International Institute of Islamic Thought and convenor of the seminar; and by Dr. Muhammad 'Abd al Hadi Abu Ridah representing the guests of the seminar.

The seminar included seven panels where twenty-one research papers, prepared for the seminar, were presented and discussed. These research papers covered the following topics:

1- Inference Methodology in the Qur'an: A Response to the Opponents of Faith, by Dr. Ahmad 'Atwah.

2- The Elements of Scientific Methodology in the Qur'an and al Sunnah, by Dr. Ghawi 'Inayah.

3- Muslim Methodology in Islamic Theology, by Dr. Fawqiyah Husayn.

4- The Methodology of Ideology in the Light of Contemporary Scientific Advances, by Dr. Muhammad 'Abd al Sattar Nassar.

5- An Overview of the Methodology of Recording History, by Dr. 'Abd al Halim 'Uways.

6- The Methodology of the Principles of Jurisprudence, by Dr. 'Abd al Hamid Madkur.

7- The Crises of Methodology in Modern Ideological Studies, by Dr. Muhammad Kamal al Din Imam.

8- The Scientific Methodology and Spirit of Ibn Khaldun and Its Relation to Islam, by Dr. 'Imad al Din Khalil. 
9- The Methodology of Epistemology in Islamic Heritage, by Dr. Ahmad Fu'ad Pasha.

10 - An evaluation of the methodological epistomology of the contributions made by Dr. Muhammad al Jundi.

11- The Relationship between Revelation and Reason, by Dr. Muhammad 'Imarah.

12- The Crises of Methodology in the Humanities, by Dr. 'Ula Anwar.

13 - The Role of Western Methodologies in the Prevalence of the Idea of Westernization and Cultural Usurpation of the Muslim Mind, by Dr. Sulayman al Khatib.

14- An Islamic Mode for the Methodology of Scientific Research, by Dr. Ahmad Fu'ad al Pasha.

15- The Benefit of Religious Methodology to Modern Sciences , by Dr. 'Abd al Latif 'Ibadah.

16- Methodology between Monotheism and Multiplicity, by Dr. Muhammad al Jundi.

17- Social Science between Its Scientific and Ideological Counterparts, by Dr. Mustafa 'Ashwi.

18- Indispensable Association of Objectivity and Analogy in Islamic Methodology, by Mr. Muhammad Amizyan.

19- Western Methodology of Knowledge in African Research: Critical Remarks and Ideas on the Alternative Islamic Methodology, by Dr. 'Ali Qurayshi.

20- Qur'anic Indication on the Methodology of Social Change, by Dr. 'Abd al Sabur Marzuq.

21- The Methodology of Dealing with Idioms, by Dr. Muhammad 'Imarah.

The Drafting Committee prepared the closing statement and recommendations which the seminar discussed in its closing session and approved as follows:

\section{The Closing Statement}

It is no secret to research scholars that methodology is of prime importance in promoting knowledge, its accuracy and advancement. Without methodology, there is no knowledge and research is nothing but a mere waste of effort and energy. That was why it was necessary to hold this seminar on issues relating to methodology in Islamic thought, considering it a necessary 
introduction to any effort exerted in the Islamic scientific arena in order to reshape both social and natural sciences into an Islamic form, particularly since Islamic ideology has its own independent and distinguishing characteristics. This requires that the methodological experiences of Islamic ideology during its golden ages be sought, to help achieve its expected upswing. In light of the scientific methodology witnessed during the golden ages, such experiences should be well understood to act as a guide throughout the journey of Islamic resurgence. That was why this seminar centered around three focal points:

First-Introducing the most important methodic techniques used by Muslim scholars in their golden ages.

Second-Introducing the most important methodic techniques used in the world, critically studying them, to reveal the crisis they face, and uncover the criticism that has been directed at them in order to define their place on the overall map of contemporary Islamic methodic research.

Third-Presenting research papers dealing with establishing an Islamic methodic pattern in the different branches of knowledge.

Perhaps the efforts that have been exerted in these areas, and the discussions that were held, were able to bring into the open the necessity of supplementing certain aspects expressed in the following recommendations.

\section{Recommendations}

1- The seminar stressed the necessity of conducting a comprehensive search of the Qur'anic verses and hadith which deal with methodology as an idiom, and classifying them according to the techniques they indicate.

2- A comprehensive search of the Qur'anic verses and Hadith should be conducted, guided by issues relating to faith, to include the Prophet's methods in confronting the opponents of faith.

3 - Projects and attempts made at updating Islamic scholastic theology, both in content and form, should be gathered and made into a textbook. Specialized scholars are to be contacted in order to accomplish this task, carefully following the most advanced scientific accomplishments, building on them, and using the new scholastic theology patterns, yet maintaining the Qur'anic methodology, when trying to comprehend matters of faith. Such a textbook must be periodically reviewed and amended. The seminar recommends that such 
a textbook be taught in all universities in the Muslim countries.

4- A comprehensive search of Qur'anic verses and Hadith should be conducted, in order to define the historical methods that were used, to help arrive at a technique for interpreting history. This should be done after an initial introduction necessary for rewriting the history of Islam and the Muslims, while on the one hand adhering to the objective approach (not picking and choosing, negatively or positively), and on the other being comprehensive, and dealing with history from a political, economic, and cultural point of view, observing the unity of the Muslim nation while rewriting its history.

5 - History scholars should go beyond the Western methodology which narrows down Muslim accomplishments in the field of interpreting history to Ibn Khaldun. Muslim historians should include in their study the methodology of early Muslim historians prior to Ibn Khaldun and his sources, and the schools that followed him, as well as develop his method and improve on it.

6- A comprehensive study of the Usũliyyūn methods in the sciences of jurisprudence, disparities and similarities, legal objectives and fundamental bases should be conducted in order to clarify the unity and variations in their approach depending on the subject-matter.

7- The seminar stresses the need for development of the science of the principles of jurisprudence in as far as its tools and content are concerned, in order that it can deal with the changing realities, thus making religious laws applicable to contemporary times. Furthermore, the seminar recommends that help should be sought from jurisprudence methodology, after its development employing techniques used in social sciences, to make it into a model pattern for these sciences to follow in their new Islamic form.

8- Modern contemporary methodology techniques of jurisprudence research and legislative methods, whether applied or still in their preparatory stages should be collected, analyzed and compared, provided the study covers as many Muslim countries as possible.

9- Muslim accomplishments in the different sciences, social or natural, should be analyzed, compared and historically researched. In conducting such a study help should be sought from old as well as modern and contemporary methods of history 
interpretation and analysis, without being bound by one particular method, which may interpret events, occurrences and stages of the juridicial and scientific history of Islam in a subjective manner.

10- A study of Muslims' contributions in the various natural sciences should be conducted by specialized scholars, each in his field of specialization, researching the process and reasons for the present Muslim backwardness, which led to a lack of creativity. They must propose solutions to the present situation.

11- The curriculums of mathematical and natural sciences in the different stages of education, in Muslim countries should be altered to include an introduction covering Muslim contributions in that science, in detail and in a way befitting these contributions.

12- Islamic civilization should be taught in all universities in the Muslim countries.

13- A course on the methodology of scientific research and objective thinking should be taught in all colleges in Muslim countries, and perhaps even in the final year in secondary schools.

14- Research should be conducted dealing with the extent to which scholastic theologians employ the scientific advancements which Muslims have achieved in their golden age in establishing the faith.

15- Qur'anic verses and Hadith which include numbers should be identified, and an accurate study of their meaning be researched.

16- Contemporary juridicial rulings should be reached, in order to fulfill the unprecedented needs of the Muslim community, provided it is made clear that the rulings are made only with regard to the variables, and not the basics, which have been established and verified by clear-cut verses which are not subject to interpretation.

17- The curriculums for the humanities should be critically examined against an original Islamic viewpoint benefitting from the constructive self-criticism of the West considering a possible introduction of a verified Islamic methodology for the study of these sciences.

18 - Furthermore, the seminar stresses the importance of continuing to take scientific and practical steps to formulate an Islamic methodology for the humanities. 
19- The methodological techniques used by Muslims in the different branches of knowledge should be identified and applied to contemporary social and natural sciences, so they would be employed in updating the methodology of these sciences and Islamically restructuring them.

20- The effects of ideology on the methodology of scientific research in the West should be identified, and the extent to which the results of gathering such information could be used in developing Islamic curriculums for these sciences should be examined.

21- Help should be sought from all that has been accomplished in the field of methodology development for the different sciences, without favoring one method over another, or tying one science to only one method and not the other. It should also be taken into consideration that these approaches should not contradict Islamic principles.

22- A search should be conducted to locate studies, translations, and researches that emphasize the role of Muslims in transferring sciences, methodologies, and researches to Western scholars, and to publicize those works, whether still in manuscript form or published, in order to establish the influence of Islamic civilization on Western thinkers and scholars. In this pursuit, only reference works and original writings which are considered authoritative in the West must be consulted.

23 - An in-depth study of the methods of cultural interaction from an Islamic viewpoint should be conducted in order to determine what to adopt and what to discard from other cultures, and in order to identify the methodology used by previous generations as well as Europeans in dealing with other cultures.

24- The seminar stresses the importance of striving to identify and uncover plans for Westernization and enunciate steps taken towards their implementation, on all levels, then analyze them in as far as content and method are concerned.

25- A study of the negative effects of Westernization on the Muslim mind should be conducted, so a method of combating them be determined.

26- The seminar stresses the importance of moral values, considering them to be the Islamic constants in any attempt to restructure the scientific methodological techniques according to Islamic patterns. 
27- A search for Qur'anic verses and Hadith dealing with social . change should be conducted, in order to clarify the Islamic methodology used. In this process, all the theoretical and scientific problems which are hindering the progress of Islamic resurgence because of lack of clarity of Islamic vision need to be analysed.

28- The seminar recommends working towards gathering and studying the terminology and concepts relating to the humanities and universal sciences, following their development or change, and examining the cultural effects of such development or change, in order to help researchers understand the meaning of these terminologies, and the extent to which they have been used.

29- A review of the curriculums for teaching Islamic law, the humanities, and universal sciences in the Muslim world should be started in light of the Islamic methodology.

30 - The seminar stresses the necessity of directing research and scholars in universities in the Muslim world, especially on the M.A. and Ph.D. levels, towards an in-depth scientific study of methodology in order to speed up the process of breaking through the current cycle of stagnation in the field of methodology.

31- The seminar further stresses the necessity of supporting the organizations which work in the scientific, intellectual and cultural areas, also the universities of Muslim countries that are concerned with Islamic methodology as the fundamental element in the cultural program, in order to re-start the upswing of the Muslim world.

32 - The two sponsoring organizations of this seminar should print and publish the research papers and discussions of this conference, and distribute same to interested parties.

33 - The two sponsoring organizations of this seminar should arrang for another similar conference to be held in order to complete the discussion of the remaining topics in the original work-sheet of this seminar. 